\title{
EXPLORING UNDERGRADUATE STUDENTS' PRODUCTIVE STRUGGLES IN A QUANTITATIVE LITERACY COURSE: IMPLICATIONS FOR THE DEVELOPMENT OF TUTORING
}

\section{Mhakure*}

e-mail: duncan.mhakure@uct.ac.za

\author{
J. Jaftha* \\ e-mail: Jacob.Jaftha@uct.ac.za
}

\section{S. Rughubar-Reddy*}

e-mail: sheena.rughubar-reddy@uct.ac.za

\section{Manzini*}

e-mail: muzi.manzini@ut.ac.za

${ }^{*}$ Centre for Higher Education Development

University of Cape Town

Cape Town, South Africa

\section{ABSTRACT}

The present study explores undergraduate students' productive struggles in a Quantitative Literacy (QL) course, when doing exercises on the statistical concept of confidence intervals (Cls) within the context of odds ratios (ORs), embedded in everyday authentic contexts. The research methodology employed in this study is lesson study, in which tutors and researchers work together to plan the research tutorial, observe and teach it, and reflect on the instruction in general within the research tutorial. Data for this study comprises video- and audio-recorded transcriptions of the observation and teaching, and reflections of tutors on research tutorials. In addition, samples of students' work and their achievements in assessments were analysed. Results from the study showed that the students' struggles were initiated when their prior knowledge was not sufficient for them to understand the concept of Cls in relation to ORs. The results also highlight some of the ways in which tutors can notice and address students' productive struggles during tutorials. Future researchers should focus on identifying which instructional approaches can promote and support prolific productive struggles for students during tutoring.

Keywords: productive struggle, quantitative literacy, tutoring

\section{INTRODUCTION}

The present study explores undergraduate students' productive struggles in a QL intervention 
course when working through a research tutorial (also referred to here simply as "a tutorial") and through exercises on the statistical concept of CIs within the context of ORs, embedded in everyday authentic contexts. In the context of this study, we define the construct of students' productive struggles during the teaching and learning of mathematics as "opportunities for delving more deeply into understanding the mathematical structure of problems and relationships among mathematical ideas, instead of simply seeking correct solutions" (Roble $2017,255)$. Hiebert and Grouws $(2007,387)$ refer to students' productive struggles simply as the "effort to make sense of mathematics, to figure something out that is not immediately apparent". A detailed description of this construct is given under the section titled "Conceptual framework" below. This study is part of a larger study whose aims are to research sustainable and practical approaches to tutoring higher education courses with a specific focus on classroom practices and discourses. Recent lines of educational research about teaching and learning (Cherney 2008; Herrmann 2013; Zepke and Leach 2010) in higher education acknowledge, on the one hand, that higher education institutions are regarded as bastions of "active, critical stimulating teaching and learning, making use of a broad range of activities to promote students' deep learning and critical engagement" (Hardman 2016, 64). On the other hand, research also shows that there is a lack of active participation by students during learning activities; according to Rocca (2010), one of the reasons for this is the poor quality of interactions between tutors and students.

There have been studies promoting cooperative learning in higher education (Baeten et al. 2010; Biggs 2011; Cavanagh 2011), which have largely focused on student-student interactions, while ignoring the roles of tutors during these interactions (Hardman 2016). As a result, very few studies have focused on student-tutor interactions during group-based teaching; these are dominated by tutor monologues punctuated by short question-and-answer sequences (De Klerk 1997), and discourses that mirror what may have been experienced by students in schools (O’Boyle 2010).

There is thus a gap in the knowledge of how higher education courses can improve active participation in learning spaces, particularly in tutorial sessions, with the aim of supporting students' productive struggles. Such support during classroom tutorials can take various forms. It includes tutors asking probing questions that require intellectual work (Pierson 2008), tutors paying greater attention to students' struggles by listening to their questions (Warshauer 2015b), tutors deliberately generating more opportunities for an impasse (Van Lehn et al. 2003), which allows tudents to "think harder", and tutors providing opportunities for whole group discussions of misconceptions and errors, thus giving rise to students using their errors as resources for learning and sense-making (Borasi 1994; Eggleton and Moldavan 2001). 
During tutorials in higher education settings, the construct of students' productive struggles can be internal, when it is experienced by individual students, in addition to being observed from a naturalistic setting of the classroom tutorial facilitation. Therefore, an investigation into the students' productive struggles with regard to CIs within the context of ORs as a statistical concept can provide insights into the types of instructional support that will enhance students' understanding of this concept.

In order to investigate the construct of students' productive struggles in an undergraduate QL course, this study sought to answer the following research questions with regard to the concept of CIs within the context of ORs: What were the students' productive struggles that were noticed by tutors during a research tutorial? How did the tutors respond to the students' productive struggles during the research tutorial? Which conceptual errors were identified by tutors during the research tutorial that were persistent in the examination?

\section{CONCEPTUAL FRAMEWORK}

In this study, we used the construct of students' productive struggles as our conceptual framework. In the learning of mathematics, struggle is defined as the "intellectual effort [that] students expend to make sense of mathematical concepts that are challenging but [that] fall within the students' reasonable capabilities" (Zeybek 2016, 396). Students' struggles are triggered when their prior knowledge is inadequate to cope conceptually with a given task or to assimilate a new concept, and thus necessitates restructuring of what they already know (Granberg 2016). Struggling students are inclined to be aware of their own knowledge gaps, and they may actively seek appropriate ways of addressing such knowledge gaps, for example, by engaging a peer or a tutor (Bullmaster-Day 2015; Loibl and Rummel 2014). Renkl and Atkinson (2007) have argued that productive struggles compel students to pay more attention to the learning objectives and the relevant concepts, with the aim of integrating them into their prior knowledge.

In some studies on the teaching and learning of mathematics, struggles convey negative beliefs about learning mathematics, such as not viewing them as opportunities to learn, and such as highlighting students' weaknesses in the subject (Borasi 1994; Hiebert and Gouws 2007; Permatasari 2016). In contrast, other studies view students' struggles as a positive necessity, which provides opportunities for students to develop a deeper understanding of mathematics (Hiebert and Grouws 2007; Kapur and Bielaczcy 2012). Researchers also argue that, when students are carefully supported towards a resolution of their struggles, it allows them to advance and develop their critical thinking skills; moreover, such struggles are deemed productive, giving rise to the term "productive struggles" (Hiebert and Grouws 2007; 
Warshauer 2015a). Supporting students' productive struggles can include, but is not limited to: giving students effective constant feedback on their work progress, correcting students' misconceptions and errors in respect of tasks in real time, asking and sequencing questions that guide students in their thinking processes (Anghileri 2006; Kartal et al. 2017), and noticing opportunities for impasse-driven learning and resolving these: "successful learning required students to reach an impasse but also, ... in general, learning did not occur without some occurrence of an impasse" (Warshauer 2015a, 391. It must be clarified that students' struggles become unproductive when they become frustrated because the tasks have no clear goals, or when they do not feel safe to fail during their attempts to solve tasks, or when students do not receive adequate support (Permatasari 2016). We have adopted the types of students' productive struggles identified by Warshauer (2015a) (see Table 2) and used them to analyse the tutors' reflections on the mathematical concept of CIs within the context of ORs. In addition, we have used the Developing Cognitive Abilities Test (DCAT), which consists of three cognition levels of basic cognitive abilities, application abilities, and critical thinking abilities (Torres and Cano 1995) to analyse the students' performance in tutorial and examination questions. DCAT levels are informed by the first five levels of Bloom's Taxonomy (i.e. excluding evaluation), namely, knowledge, comprehension, application, analysis, and synthesis (Omar et al. 2012; Thompson et al. 2008).

\section{METHODOLOGY}

\section{Participants}

One hundred and forty-six undergraduate first year students from the Humanities Faculty at the University of Cape Town, who were enrolled in a QL intervention course, participated in this study. This course is intended to equip them with the quantitative reasoning skills they need in order to cope with the quantitative demands of their discipline - Psychology, and with the future quantitative demands of the workplace. The QL course is not a mathematics course, although students are taught some statistical and mathematical concepts, which they will need to study research methods in the second and/or third year of their discipline. In this study, we explore the students' productive struggles in relation to the statistical concept of CIs within the context of ORs. The students in the QL course were divided into eight tutorial groups, with a maximum of twenty students each, and each tutorial group was assigned a tutor. However, only two of the tutorial groups and their tutors were observed and video-recorded. In addition, we managed to analyze the students' written solutions from an examination question on CIs within the context of $O R s$. 


\section{Procedure}

This study uses the lesson study as a research methodology (Hart, Alston and Murata 2011) to explore how tutors and researchers work together to plan, observe and teach, and reflect on a research tutorial. A research tutorial creates a unique learning environment for tutors to share classroom practice experiences amongst themselves and researchers. The implicit and organic sharing of classroom practice experiences between tutors and researchers leads to the professional development of tutors. The two main data sources of this study were the analyses of the one hundred and forty-six students' written solutions from an examination question on CIs within the context of ORs, and the tutors' own reflections on the students' productive struggles with the concept of CIs within the context of ORs. After the research tutorials were video recorded, tutors were given the opportunity to watch the videos of their own tutorials, and to reflect on their individual tutorials using a prescribed template. The aim was to compare the students' productive struggles as observed by tutors during the research tutorial with the students' conceptual understanding in the examination question - and to see how the contrast between the two can be used to improve and develop the tutoring.

\section{FINDINGS}

In line with the aims of this study, we firstly explore the nature of the students' productive struggles in a research tutorial episode on CIs within the context of ORs embedded in an everyday context, by analysing the reflections of two tutors. Secondly, we analyse the students' conceptual understandings as these manifested during an examination question on CIs within the context of ORs in the QL course. Lastly, we compare the students' productive struggles in the research tutorial with the students' conceptual understandings in relation to the examination question.

\section{Tutor's reflections on Cls within the context of ORs}

Below is the tutorial task that was facilitated by the two tutors. For the sake of anonymity, the two tutors are referred to as Ted and Kim. After facilitating their tutorials, Ted and Kim reflected on the students' productive struggles during the tutorials. Their reflections were analysed by using an adapted version of the productive struggle framework that had been developed by Warshauer (2014). This productive framework comprises four types of struggles, namely: getting started, carrying out a process, uncertainty in explaining and sense making, and expressing misconceptions and errors.

Tutorial Task: Flisher et al. (2003) documented the prevalence of the use of cigarettes, 
alcohol and cannabis among high school students in Cape Town. Their results were investigated for associations between substance use and, amongst other things, potentially problematic school behaviour. The associations between cigarette smoking (in the month prior to the survey) and (i) absenteeism and (ii) poor school progress for three different student groups are presented in Table 1.

Table 1: Odds ratios $(95 \% \mathrm{Cls})$ for the use of cigarettes in the previous month, for student groups $\mathrm{A}$, $B$ and $C$

\begin{tabular}{|l|c|c|}
\hline & \multirow{2}{*}{ Group } & Cigarettes \\
\cline { 3 - 3 } & & Odds Ratio (95\% CI) \\
\hline Absenteeism in the 15t term & A & $1.1(0.7-1.7){ }^{*}$ \\
& B & $1.9(1.8-2.0)^{*}$ \\
\hline Poor school progress: & C & $2.2(2.1-2.3)^{*}$ \\
repeating a grade & A & $(0.7-1.7)$ \\
& B & $2.4(2.0-2.9)^{*}$ \\
& C & $1.3(0.9-1.8)$ \\
\hline
\end{tabular}

Footnote * $p<0.05$

Tutorial task questions: (a) Which group of students shows a significant association between cigarette smoking (in the previous month) and repeating a grade? (b) What other information in the table supports your answers in (a)? (c) What statement can be made about group C students regarding the association between recent cigarette smoking and absenteeism in the first term? (d) What can be inferred from the 95 per cent CI (2.1-2.3) for group C students? (e) What does the 95 per cent CI for the OR in relation to Group A students tell you about the association between recent cigarette smoking and repeating a grade in this group? (f) What information in the table indicates that there is a good chance that the actual OR values for Group B are "significantly" different from those of Group A, with regard to cigarette smoking and absenteeism? (g) What does $\mathrm{p}<0.05$ tell us about the chance of making an error in rejecting the null hypothesis? (h) What value of "p" is usually used to indicate that there is no statistically significant difference between two variables?

\section{DCAT categorisation of tutorial task questions}

One of the aims of this study was to identify conceptual errors that were persistent in both the tutorial and the examination. In order to achieve this, we decided to apply the DCAT categorisation to the task questions of the tutorial and to the examination question. The DCAT categorisation and subsequent analysis of the task question of the examination is presented in the section titled "Analysis of students' written work" below. In this section, as illustrated in Table 2, the DCAT categorisation of the tutorial task questions was used to group these questions into three cognitive levels, namely: basic cognitive abilities, application abilities, and 
critical thinking abilities. For each of the tutorial task questions, the expected competencies are given, in addition to the DCAT cognition level.

Table 2: DCAT categorisation of the tutorial task questions

\begin{tabular}{|c|c|c|}
\hline $\begin{array}{c}\text { Tutorial Task } \\
\text { Question }\end{array}$ & Expected Competency & DCAT cognitive level \\
\hline (a) & $\begin{array}{l}\text { Recalling knowledge that significant association between } \\
\text { variables depends on } p<0.05\end{array}$ & Basic Cognitive Abilities \\
\hline (b) & $\begin{array}{l}\text { Recalling knowledge that significant association between } \\
\text { variables happens when the OR value of } 1 \text { is not included in the } \\
\mathrm{Cl} \text {. }\end{array}$ & Basic Cognitive Abilities \\
\hline (c) & $\begin{array}{l}\text { Recognising that Group } C \text { has the characteristics of the } \\
\text { question asked before in (a) and applying that to formulate a } \\
\text { statement. }\end{array}$ & Application Abilities \\
\hline (d) & $\begin{array}{l}\text { Recognising that the } \mathrm{Cl} \text { has the characteristics of the question } \\
\text { asked before in (b) and applying this to formulate a statement. }\end{array}$ & Application Abilities \\
\hline (e) & Recalling definition of a $95 \% \mathrm{Cl}$ & Basic Cognitive Abilities \\
\hline (f) & $\begin{array}{l}\text { Applying the knowledge that sample statistics are significantly } \\
\text { different when there are non-overlapping Cls }\end{array}$ & Application Abilities \\
\hline (g) & $\begin{array}{l}\text { Applying the knowledge that } \mathrm{p}<0.05 \text { implies that the probability } \\
\text { of making an error in rejecting } \mathrm{H}_{0} \text { is small }\end{array}$ & Application Abilities \\
\hline (h) & $\begin{array}{l}\text { Recognising that that no evidence of statistical difference is } \\
\text { equivalent to the probability of rejecting } \mathrm{H}_{0} \text { is not small enough, } \\
\text { i.e. } p \geq 0 \text {. }\end{array}$ & Critical Thinking Abilities \\
\hline
\end{tabular}

The DCAT categorisation in Table 2 was agreed to by consensus by four independent QL facilitators to ensure the trustworthiness of the categorisation (Yin 2017). The first QL facilitator analysed and categorised all the tutorial task question into the DCAT cognitive levels, and then made the categorisation process available for verification by the other three QL facilitators (Ketelaar et al. 2012). After several discussions, our categorisations were refined until consensus was reached on every question. Although not referred to directly in the discussion of the tutors' reflections, the categorisation of the tutorial task questions using the DCAT cognitive levels revealed why students found some tutorial task questions more challenging than others.

We categorised the reflections of Ted and Kim on students' productive struggles (Warshauer 2014; Zeybek 2016) on CIs within the context of ORs. This was done by assigning each of their reflections to the four types of struggles (see Table 3). To ensure the trustworthiness of our categorisations of the students' productive struggles from the tutors' reflections, the categorisations were done by all three researchers who had thorough knowledge of the QL course, and the teaching of OR and CI. The aim was to arrive at some agreement with regard to our ratings. After a number of discussions, agreement was reached on the final categorisation. 
Table 3: Descriptions of the types of productive struggles, and the existence of the struggles in the tutor's reflections

\begin{tabular}{|l|l|c|c|}
\hline \multicolumn{1}{|c|}{$\begin{array}{c}\text { Type of } \\
\text { struggle }\end{array}$} & \multicolumn{1}{c|}{ Description of the struggle } & \multicolumn{1}{c|}{$\begin{array}{c}\text { Existence of the struggle } \\
\text { in the tutor's reflections }\end{array}$} \\
\cline { 2 - 4 } & \multicolumn{1}{|c|}{ Ted } & Kim \\
\hline Getting started & $\begin{array}{l}\text { Confusion about what the question is asking. Do not } \\
\text { remember work on OR and Cl. No work on paper. Gesture } \\
\text { uncertainty and have given up. Fail to interpret the } \\
\text { information given in the Table 1 of the context. }\end{array}$ & $\sqrt{ }$ & $\sqrt{ }$ \\
\hline $\begin{array}{l}\text { Carrying out a } \\
\text { process }\end{array}$ & $\begin{array}{l}\text { Students get started but encounter an impasse. Fail to see } \\
\text { the relationship between the current task on OR and the } \\
\text { previous work. Have forgotten the definition of OR and Cl } \\
\text { as they relate to samples and populations. }\end{array}$ & $\sqrt{ }$ & $\sqrt{ }$ \\
\hline $\begin{array}{l}\text { Uncertainty in } \\
\text { explaining and } \\
\text { sense-making }\end{array}$ & $\begin{array}{l}\text { Students have difficulty in explaining their work. Unable to } \\
\text { make sense of their solutions. Unclear on the } \\
\text { interpretation of the Cl when they contain 1. }\end{array}$ & $\sqrt{ }$ & $\sqrt{ }$ \\
\hline $\begin{array}{l}\text { Expressing } \\
\text { misconception } \\
\text { and errors }\end{array}$ & $\begin{array}{l}\text { Misconceptions related to conceptualising OR - } \\
\text { expressing OR as a percentage. Could not distinguish } \\
\text { between "exposures" and "effect" variables. Interpretation } \\
\text { of the p-values. }\end{array}$ & $\sqrt{ }$ & $\sqrt{ }$ \\
\hline
\end{tabular}

Adapted from Warshauer (2015a, 385)

Footnote: $\sqrt{ }$ - means at least one of the descriptions of the struggle was observed.

Table 3 summarises the types of productive struggles encountered and the tutors' reflections that emerged from our data analyses. Although Ted and Kim used distinct groups during their tutorial facilitations, both observed all four types of productive struggles from their respective groups.

We now discuss each of the students' productive struggles with respect to the tutors' reflections and the tutors' actions.

\section{Getting started}

This type of productive struggle occurs when students are attempting tasks that are complex and unfamiliar and that require a higher-level cognitive ability (Warshauer 2014; Zeybek 2016). In this study, a task (see the tutorial task) is a higher-level cognitive demand task that required students to conceptualise ORs and CIs as they appeared within a given context. The first challenge that students encounter is to have a general understanding of the information presented in Table 1, which means understanding how Table 1 was constructed. At the beginning of the tutorial, Kim realised that her students did not understand the tasks; she states: "Almost the whole class had difficulty in starting in one way or another reading the table and figuring how the information from the table was obtained". Ted had a similar experience with his group; he claims that "Students struggled to use their prior knowledge to read the table OR. For example, students did not seem to know what the table referred to". In order to help students to unpack the table, both Ted and Kim indicated that they used directed guidance - a technique that involves redirecting students to focus on smaller sections of the table before focusing on 
the table in its entirety (Permatasari 2016; Warshauer 2015b). In addition, Kim also said she used the technique of telling: she provided additional information, simplified information, suggested alternative strategies, and evaluated students' solutions to help them overcome their struggles (Hiebert and Grouws 2007; Warshauer 2015a).

\section{Carrying out a process}

This relates to the students finding it difficult to verbalise "some plan [process] for achieving the goal of the task but encountered an impasse" (Permatasari 2016, 96); such an inability by students to verbalise the thinking and reasoning processes does not always mean that the students arrived at the wrong answers. Kim posited that "Students also seemed to struggle with the new concept of the odds ratios; I asked them how the odds ratios were calculated. One student responded by saying 'smokers/absent students"'. This answer was incorrect, and thus prompted Kim to use probing guidance to engage the students further with unpacking Table 1. Probing guidance is a technique commonly used by tutors to seek explanations that make students' errors and misconceptions noticeable (Bruning et al. 2011; Warshauer 2015a). When students were asked the question, "What can be inferred from the 95 per cent CI (2.1-2.3) for group C students?", they failed to realise that high school students in Group C who smoked were more than double as likely to have been absent in the first term than students who had not smoked recently. In their responses, students could only say that Group C students had a significant association, but they did not specify the magnitude of the association. On realising the latter, Ted said, "I probed them on their answer and it seemed to help but for some I resorted to telling". Telling is a technique where a tutor provides more information to students so that students can overcome their struggle (Permatasari 2016; Zeybek 2016).

\section{Uncertainty in explanation and sense making}

This occurs when students fail to make sense of their solutions. For example, when students were asked "(a) Which group of students shows a significant association between cigarette smoking (in the previous month) and repeating a grade?", the general response was Group B, which was the correct answer. When probed to give reasons for choosing Group B, the students said it had the biggest OR, which was the incorrect response. Kim explains: "What they [students] did was to look at what the largest odd ratio in the table was, and because Group B had the highest overall odd ratio, it was the one showing a significant difference between cigarette smoking and repeating the grade". However, the reason why Group B was the correct answer is that the CI for Group B does not contain an OR of 1, hence there is a statistically significant difference between cigarette smoking and repeating a grade. Ted had a similar 
experience with his tutorial group; he reflects, "One student was pleased when she finally understood that, if the confidence interval contains 1 , there is no significant association between the variables".

\section{Expressing misconception and errors}

These refer to struggles that involve students' misconceptions on OR, CI, exposures and effects, and the interpretation of probability values (p-values). When students were asked the question "(b) What other information in the table supports your answers in (a)?" The obvious answer was that the CI does not contain 1; however, according to Kim, "A lot of students who noticed the asterisk (see footnote on Table 1) were able to conclude that the p-value was less than the critical value (0.05) and that this shows significant association". The misconception with regard to the latter was that some students failed to realise that either the p-value or the CI can be used to tell significance differences between two variables. Students struggled to find solutions to some of the questions where they were required to interpret data within a particular population, as opposed to across populations, for example, with regard to the question "(f) What information in the table indicates that there is a good chance that the actual OR values for Group B is 'significantly' different from that of Group A, with regard to cigarette smoking and absenteeism?" The solution simply required students to mention that the 95 per cent CI of the OR for Group B does not overlap with that of Group A. However, students had misconceptions about this, as they mentioned that the OR in Group B (2.2) was different from the OR of Group A (1.1), in addition to saying that the CI for Group A contains 1. Kim summarises this by saying that "they [students] were finding it difficult to shift their mind from analysing data within a population to analysing data across different populations". Ted had to explain to students that " $\mathrm{A}, \mathrm{B}$, and $\mathrm{C}$ were actually different populations and that these populations could be subdivided into four groups. Those [students] that smoked and repeated and those that smoked and did not repeat etc." Part of Ted's explanation speaks to some of the errors that students make about the identification of "exposure" and "effect" variables when unpacking OR contexts.

\section{Analyses of students' written work on an examination question on Cls within the context of ORs}

In the previous section, we analysed the tutors' reflection on the students' productive struggles in relation to the concepts CIs within the context of ORs. The objective of this section is to illustrate and analyse some of the students' written work on an examination question dealing with their conceptual understandings of CIs within the context of ORs. For us this is important, because we want to find out if there are any similarities between what the tutors observed as 
students' productive struggles and how the students performed with regard to these concepts. Part of the analyses that we carried out involved looking at how the students performed on each of the five questions, which were aimed at testing the students' procedural and conceptual understanding of CIs within the context of ORs. Conceptual understanding refers to interpreting and applying concepts to mathematical situations that are unfamiliar, whereas procedural understanding means showing and manipulating "mathematical skills, such as calculations, rules, formulae, algorithms and symbols" (Engelbrecht, Bergsten and Kågesten 2009, 932). In order to ensure construct validity, the examination items were thoroughly and independently scrutinised by other colleagues (four QL facilitators and an external examiner) thus establishing suitable cognitive levels in relation to the examination questions. In addition, the students' written work was also subjected to the scrutiny of the external examiner after marking. Whilst we focus on illustrating some of the interesting students' written solutions within the three categories of basic cognitive abilities, application abilities, and critical and thinking abilities, our general discussions do not necessarily make direct connections to these students' written work that was chosen for illustration.

Table 4: Odds Ratios (95\% Cl) for Partner Violence Reported by Men

\begin{tabular}{|c|l|l|}
\hline Demographic variable & Perpetrator & Victim \\
\hline Race: & & 1.00 \\
\hline Black & 1.00 & $1.29(0.6-2.8)$ \\
\hline Coloured & $1.05(0.6-1.9)$ & $1.00(0.3-3.1)$ \\
\hline White & $\mathbf{2 . 2 9}(0.6-9.5)$ & $1.67(0.7-4.1)$ \\
\hline Indian & $1.62(0.5-5.5)$ & $1.66(0.5-5.6)$ \\
\hline Education: & & $1.16(0.5-2.5)$ \\
\hline None & $2.35(0.7-7.9)$ & $1.40(0.7-2.9)$ \\
\hline Grade 1-7 & $1.98(0.7-5.5)$ & $1.76(0.7-4.4)$ \\
\hline Grade 8-11 & $2.55(0.9-7.5)$ & 1.00 \\
\hline Grade 12 & $2.43(0.9-6.3)$ & 1.00 \\
\hline Post-matric qualification & & \\
\hline
\end{tabular}

Examination Question: The following excerpt is adapted from the article: Gass et al. (2010), "Gender differences in risk for intimate partner violence among South African adults", Journal of Interpersonal Violence 26(14): 2764-2789. This study reports on a nationally representative cross-sectional study aimed at analysing gender differences in risk for intimate partner violence (IPV) victimisation and perpetration according to childhood and adult risk factors. The authors examined data from 1715 South African men and women currently married or cohabiting adults.

Table 5 illustrates how students' written responses were analysed, with each question 
being allocated a score of 2 . The students' performance with regard to the questions was categorised as: high - if a student scores a 2, moderately high - if the student scored 1.5, average - for a score of 1 , moderately low - for a score of 0.5, low - if the student scored 0 , and no attempts - if the student left the question blank. In addition to the information displayed in Table 5, we further classified examination Questions 1 to 5 using DCAT. The students' performance in the examination questions was analysed by using the stated levels of DCAT. From Table 5, Questions 1 and 2, Questions 3 and 4, and Question 5 are assigned to the categories of basic cognitive abilities, application abilities, and critical thinking abilities, respectively.

Table 5: Number of students who performed in designated categories

\begin{tabular}{|l|c|c|c|c|c|c|}
\hline \multirow{2}{*}{ Question description } & \multicolumn{3}{|c|}{ Number of students who performed in the designated categories } \\
\cline { 2 - 7 } & High & $\begin{array}{c}\text { Moderately } \\
\text { High }\end{array}$ & Average & $\begin{array}{c}\text { Moderately } \\
\text { Low }\end{array}$ & Low & $\begin{array}{c}\text { No } \\
\text { attempts }\end{array}$ \\
\hline $\begin{array}{l}\text { Identify the "exposure" and "effect" variables } \\
\text { in this study }\end{array}$ & 7 & 26 & 25 & 66 & 22 & 0 \\
\hline $\begin{array}{l}\text { Consider the following statement from the } \\
\text { article (not shown above): Men who } \\
\text { experienced physical abuse at home during } \\
\text { childhood were 2 (95\% C: 1.1-4.3) times as } \\
\text { likely to report perpetration of IPV. What two } \\
\text { things are being compared in this statement? }\end{array}$ & 3 & 5 & 50 & 62 & 26 & 0 \\
\hline $\begin{array}{l}\text { Describe, in the context, the meaning of the } \\
\text { number 2.29 given in bold in Table 1. }\end{array}$ & 18 & 26 & 56 & 41 & 3 & 2 \\
\hline $\begin{array}{l}\text { Describe, in the context, the meaning of the } \\
\text { numbers (0.5-2.5) in bold in the table. }\end{array}$ & 1 & 11 & 63 & 47 & 20 & 4 \\
\hline $\begin{array}{l}\text { For which grades is there a significant } \\
\text { difference in the likelihood of victimisation } \\
\text { reported by men when compared to a post- } \\
\text { matric qualification? Explain your answer. }\end{array}$ & 12 & 0 & 17 & 1 & 100 & 16 \\
\hline
\end{tabular}

\section{Students' performance in the category of basic cognitive abilities}

The examination questions in this category, which equate to the category levels of knowledge and comprehension in respect of Bloom's taxonomy, were intended to draw on factual answers, test recall and test understanding of the meanings of "exposure" and "effect", and translate knowledge into new contexts through interpretations of the concept of ORs and CIs (see Questions 1 and 2).

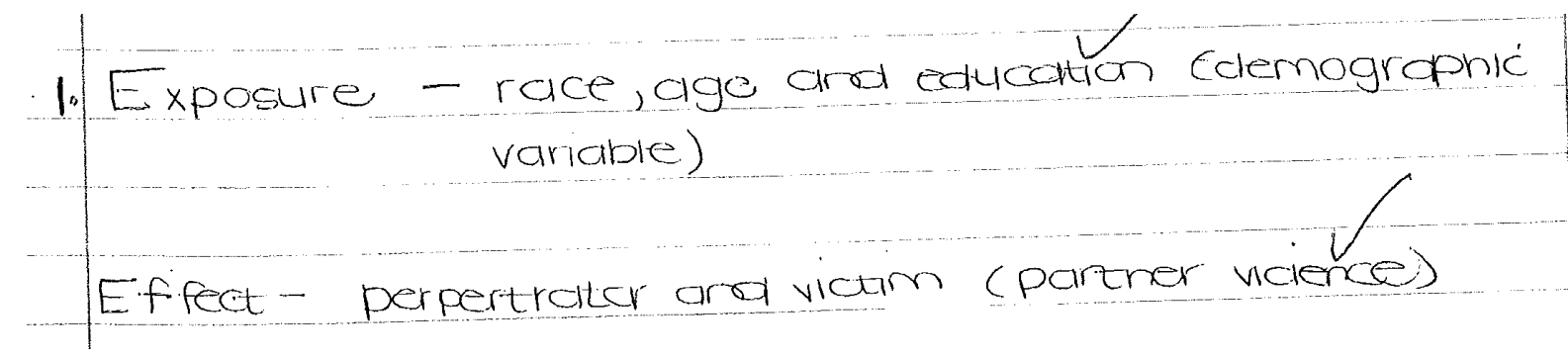


Figure 1: A student's solution to Question 1

The aim of this question was for the student to remember facts and to recall the facts as they had been taught and learned in context. Here the facts relate to the variables of exposure and effect, which are key concepts when interpreting OR. Forty per cent of the students scored 1 and above on this question, and all students attempted to answer the question. Common misconceptions on this question included, but were not limited to: students swapping the exposure and the effect variables; identifying married and cohabiting men and women as exposures; and exposure referring to either males or females, among others.

Question 2 tested students' understanding of OR, particularly the notion that the OR is about comparing two things, which in this case are the IPV perpetration by "men who experience physical abuse at home during childhood" and "men who didn't experience physical abuse at home during childhood". Similar to Question 1, 40 per cent of the students scored at least 1. Interestingly, the students' solutions to question were more specific, in that the word "reported" was inserted in the answers. In the case below, the student made reference to the heading of Table 1, which we thought quite astute.

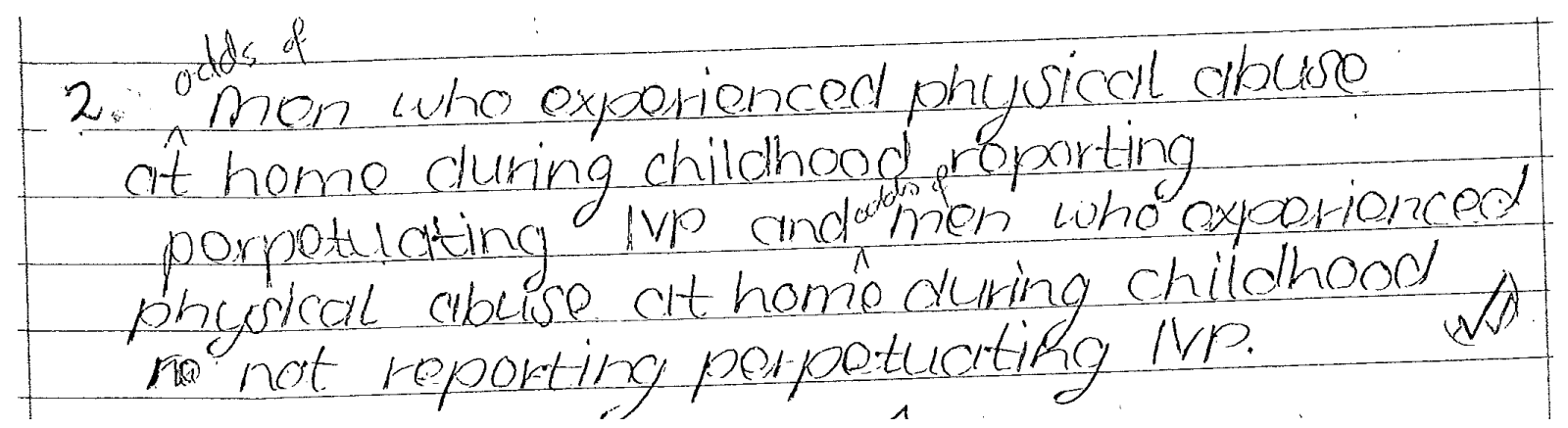

Figure 2: A student's solution to Question 2.

Students performed poorly in relation to this question, with a common answer to this question being "men who experienced physical abuse at home during childhood and men who reported perpetration of IPV'. As a result, many students only had the first part of the answer correct.

\section{Students' performance in the category of application abilities}

In the category of application abilities, we sought to analyse students' performance in terms of their abilities to apply their knowledge of ORs and CIs to new and concrete authentic situations (see Questions 3 and 4). 
3. White males are 2,29 times as litely to perpetrate intimate partwer violence than winite females.

Figure 3: A student's solution to Question 3.

This question was designed to test the students' application of the definition of ORs. The idea was that students should be able associate the number " 2.29 " with: the sample of the study, white men, using black men as a point of reference, as their OR is equal to 1. A student's solution illustrated in Figure 3 above shows that the student missed two important issues: Firstly, s/he failed to mention directly the "sample", and secondly, the student erroneously compared white males to white females, although females are not mentioned anywhere in the context. Other students presented misconceptions in their solution by stating that " $2.29 \%$ of white men in the sample reported perpetration of IPV in South Africa”. Writing an OR as a percentage is an indication that these students lacked understanding about ORs. Even though the students performed generally well in this question, with about 68 per cent of them scoring at least a point, the point was gained for reading the table correctly rather than for interpreting the value of the OR.

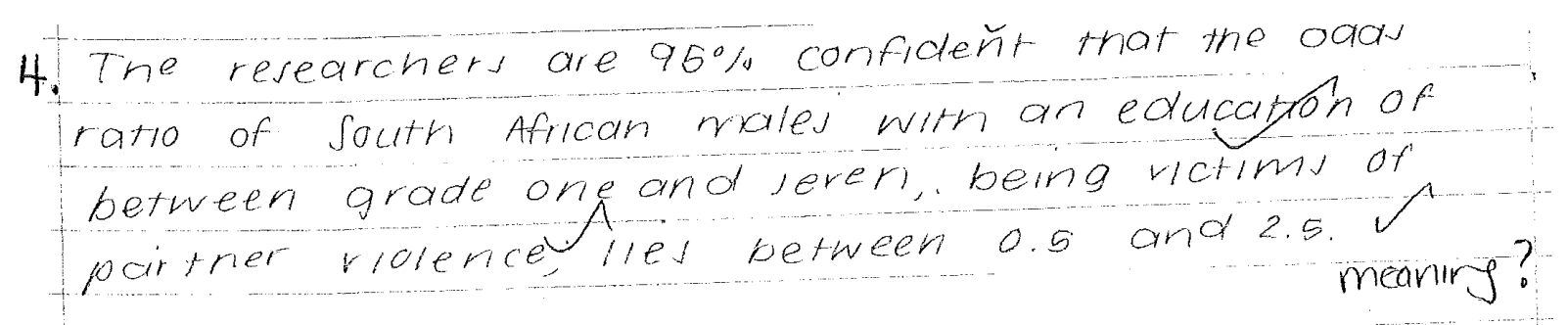

Figure 4: A student's solution to Question 4

Question 4 was intended to test the students' ability to apply the definition of CI when associated with ORs in context. We wanted the students to state in context that the OR in the true population (of South Africa) for men with Grades 1-7 lies between 0.5 and 2.5. The illustrative example in Figure 4 is partially correct because there is no direct comparison between "men with Grades 1-7" and "men with a post-matric qualification". The students were expected to state something along these lines: "In South Africa (or in the true population), men with grades 1-7 are between 0.5 and 2.5 times as likely to report being victimised as men with a post-matric qualification". Some students showed a lack of conceptual understanding of what they were being tested on and, as was the case in Question 3, they interpreted the numbers " 0.5 " 
and " 2.5 " as percentages. In terms of overall performance, only about 51 per cent of the students scored at least 1 in Question 4.

\section{Students' performance in the category of critical and thinking abilities}

The categories of analysis and synthesis in Bloom's taxonomy are combined to form the critical and thinking abilities category. In this category, we are interested in how the students break "material into its constituent parts and [how they determine] how the parts relate to one another and to the overall structure or purpose" (Thompson et al. 2008, 158). More specifically, in Question 5, students are expected to distinguish between grades and the likelihood of victimisation reported by men using CIs. In order to answer Question 5, students are expected to examine whether the CIs contained 1 or not.

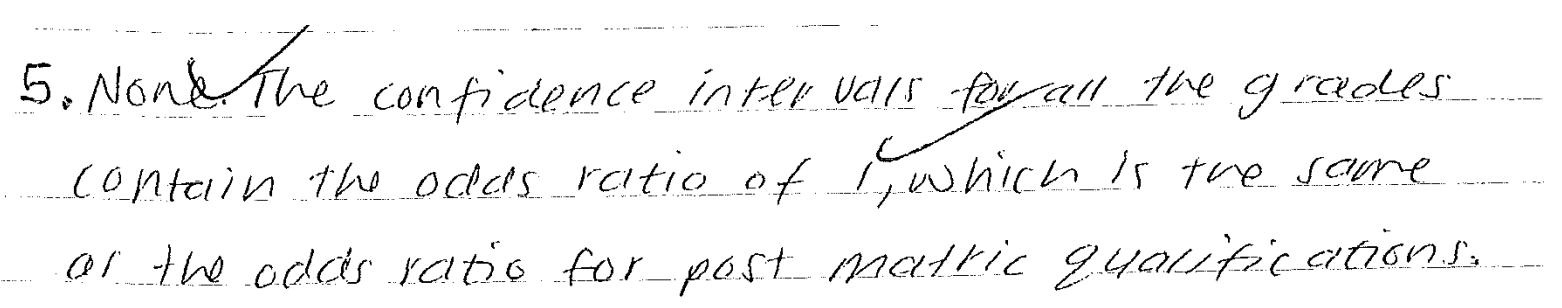

Figure 5: A student's solution to Question 5.

The aim of this question was for the students to realise that all four educational categories (viz., none, Grades 1-7, Grades 8-11, and Grade 12) had CIs that contain 1. In addition, all four were being compared to the category of post-matric qualifications, whose OR is pegged at 1. Figure 5 shows the correct solution for Question 5; namely, since the CIs for all the categories contain 1 , none are significantly different from the post-matric qualification category. Our observations show that students performed poorly on this question. Some students mentioned that the intervals in the four categories were overlapping; although true, it was irrelevant in this question. The notion that the CI contained 1 was absent from most of the students' answers. There were also many instances where students argued that, since the ORs of the four categories were bigger than 1, this meant that there was a significant difference between them and the category of post-matric qualification. About 68 per cent of the students had a score of zero, and about 11 per cent did not attempt to answer the question at all.

\section{CONCLUDING DISCUSSION}

This study, which is a pilot, investigated the construct of students' productive struggles in an undergraduate QL course at a tertiary institution. More specifically, the study sought to 
investigate students' productive struggles with regard to CIs within the context of ORs as a statistical concept in a classroom tutorial. With our key focus on the concept of CIs within the context of ORs, we began this study with the aim of identifying: the students' struggle that was noticeable during the tutorial, how the tutors responded to the students' productive struggle when they noticed it during the tutorial, and the conceptual errors from the tutorials that were persistent in the examination.

The main data sources of the study were, firstly, analyses of the two tutors' reflections on the students' productive struggles, using Warshauer (2015b)'s productive struggles framework, and, secondly, analyses of the students' conceptual understanding of the concept of CIswithin the context of ORs.

The findings of the study show that there were four types of students' struggles that were identified and observed by the tutors, namely: getting started, carrying out a process, uncertainty in explanation and sense making, and expressing misconceptions and errors (Warshauer 2014; Warshauer 2015a; Zeybek 2016).

An important observation from the tutors' reflections was that, within one tutorial task question, more than one type of students' struggle could be identified within the tutorial group, and at an individual level. In responding to these students' struggles, tutors had to choose whether a particular struggle needed to be addressed at the level of the tutorial group or at the level of the individual. From the tutors' reflections, we see that the tutors were using three types of responses when they were attending to the students' struggles: telling, directed guidance, and probing guidance. These types of responses, which were driven by the quality of questioning by the tutors, were critical in the learning of the concepts CI, OR and CIs for ORs. For example, with reference to directed guidance and probing guidance Stigler and Hiebert (2004) assert that such guidance can "provide students with opportunities to think more deeply about mathematical concepts" (p. 13).

A comparison between the students' conceptual understandings from using the tutors' reflections, and the students' conceptual understanding as demonstrated in their solutions in the examination on the concept of CIs within the context of ORs showed some similarities. Both the tutorial questions and the examination question required students to understand and interpret a CI, to understand and interpret an OR and to explain a CI in the context of ORs. The contexts were different, and the examination added the complexity of making the OR with reference to a category in the table. However, it is appropriate to acknowledge that undergraduate students in this QL course find the concepts taught on this topic quite challenging. This is exacerbated by the fact that these concepts are embedded in everyday life contexts, with which the students might not be familiar. The findings also show that students found the tutorial task questions and 
the examination questions very challenging, in terms of the DCAT's cognitive levels of application abilities and critical thinking abilities, especially with regard to interpreting or explaining CIs within the context of ORs. A possible explanation may be that students' conceptual challenges at the latter levels were not resolved in the tutorials, and hence persisted in the examination.

Through the tutor professional development, tutors acquire the requisite mathematical knowledge for teaching which they need to facilitate tutorials, in other words, the professional development of tutors leads to improved tutorials facilitation. In addition, we argue that, improved tutorial facilitation results in better performance by students in the assessments.

We already alluded to the fact that this study is part of a bigger project whose aims are to develop tutoring in a QL course for undergraduate students in higher education. This pilot study has enabled us to analyse tutors' reflections on the students' productive struggles with the concept of CIs within the context of ORs; we have also analysed students' written examination solutions on the same concept. The question we need to ask ourselves is: how do we use the findings of this study to improve tutoring in our courses? The implications of this study are: first, to provide guidance to the designers of the tutoring programme on how tutors can facilitate and provide opportunities for students to think more deeply about mathematics by paying attention to students' productive struggles. Second, that it contributes how tutors can be empowered to notice and make confident and professionally informed decisions about the students' productive struggles during learning. When tutors theorise their teaching, they are likely to encourage greater student participation and higher levels of student cognitive engagement, resulting in students experiencing deep conceptual understanding of the mathematics. Last, that the majority of postgraduate tutors end being academics, we argue that this study contributes to the training of future academics with sound pedagogical knowledge. For future research, our focus will be directed at the level of questioning that the tutors use when responding to or addressing the students' productive struggles in the QL course. Equally important and related to the latter, is to seek some understanding of the tutors' mathematical knowledge as it relates to teaching.

\section{REFERENCES}

Anghileri, Julia. 2006. Scaffolding practices that enhance mathematics learning. Journal of Mathematics Teacher Education 9(1): 33-52.

Baeten, Marlies, Eva Kyndt, Katrien Struyven and Filip Dochy. 2010. Using student-centred learning environments to stimulate deep approaches to learning: Factors encouraging or discouraging their effectiveness. Educational Research Review 5(3): 243-260. 
Biggs, John B. 2011. Teaching for quality learning at university: What the student does. McGraw-Hill Education (UK).

Borasi, Raffaella. 1994. Capitalizing on errors as "springboards for inquiry": A teaching experiment. Journal for Research in Mathematics Education 25(2): 166-208.

Bruning, Roger H., Gregory J. Schraw and Royce R. Ronning. 2011. Cognitive psychology and instruction. Boston, MA: Pearson Education, Inc.

Bullmaster-Day, M. L. 2015. Productive struggle for deeper learning. White paper. WeAreTeachers: http://www.weareteachers.com/docs/default-source/triumphlearninglessons/triumph-learning-productive-struggle-white-paper.pdf (Accessed 1 April 2016).

Cavanagh, Michael. 2011. Students' experiences of active engagement through cooperative learning activities in lectures. Active Learning in Higher Education 12(1): 23-33.

Cherney, Isabelle D. 2008. The effects of active learning on students' memories for course content. Active Learning in Higher Education 9(2): 152-171.

De Klerk, Vivian. 1997. Interaction patterns in university education. In Encyclopaedia of Language and Education Vol 3, ed. B. Davies and D. Corson, 207-216. Dordrecht: Kluwer Academic Publishers.

Eggleton, Patrick J. and Carla C. Moldavan. 2001. The value of mistakes. Mathematics Teaching in the Middle School 7(1): 42-47.

Engelbrecht, Johann, Christer Bergsten and Owe Kågesten. 2009. Undergraduate students' preference for procedural to conceptual solutions to mathematical problems. International Journal of Mathematical Education in Science and Technology 40(7): 927-940.

Granberg, Carina. 2016. Discovering and addressing errors during mathematics problemsolving: A productive struggle? The Journal of Mathematical Behavior 42: 33-48.

Gass, Jesse D., Dan J. Stein, David R. Williams, and Soraya Seedat. 2010. Gender differences in risk for intimate partner violence among South African adults. Journal of Interpersonal Violence 26(14): 2764-2789.

Hardman, Jan. 2016. Tutor-student interaction in seminar teaching: Implications for professional development. Active Learning in Higher Education 17(1): 63-76.

Hart, Lynn C., Alice S. Alston and Aki Murata. 2011. Lesson study research and practice in mathematics education. New York: Springer.

Herrmann, Kim J. 2013. The impact of cooperative learning on student engagement: Results from an intervention. Active Learning in Higher Education 14(3): 175-187.

Hiebert, James and Douglas A. Grouws. 2007. The effects of classroom mathematics teaching on students' learning. In Second handbook of research on mathematics teaching and learning, ed. J. Frank and K. Lester, 371-404. Charlotte: Information Age. 
Kapur, Manu and Katerine Bielaczy. 2012. Designing for productive failure. Journal of the Learning Sciences 21(1): 45-83.

Kartal, Ozgul, Gorjana Popovic, Susie Morrissey and Lamont Holifield. 2017. Students' productive struggle through mathematical modeling. Illinois Mathematics Teacher 64(1): 1-9.

Ketelaar, Evelien, Douwe Beijaard, Henny P. A. Boshuizen and Perry J. Den Brok. 2012. Teachers' positioning towards an educational innovation in the light of ownership, sensemaking and agency. Teaching and Teacher Education 28(2): 273-282.

Loibl, Katharina and Rummel Nikol. 2014. Knowing what you don't know makes failure productive. Learning and Instruction 34: 74-85.

O'Boyle, Aisling. 2010. The dialogic construction of knowledge in university classroom talk: A corpus study of spoken academic discourse. Unpublished PhD Thesis, Queen's University, Canada, Kingston, ON.

Omar, Nazlia, Syahidah Sufi Haris, Rosilah Hassan, Haslina Arshad, Masura Rahmat, Noor Faridatul Ainun Zainal and Rozli Zulkifli. 2012. Automated analysis of exam questions according to Bloom's taxonomy. Procedia-Social and Behavioural Sciences 59: 297-303.

Permatasari, Dian. 2016. The role of productive struggle to enhance learning mathematics with understanding. Proceedings of $3^{\text {rd }}$ International Conference on Research, Implementation and Education of Mathematics and Science, 95-100. 16-17 May 2016. Yogyakarta. Jakarta.

Pierson, Jessica L. 2008. The relationship between patterns of classroom discourse and mathematical learning. Unpublished dissertation. The University of Texas at Austin. Austin.

Renkl, Alexander and Robert K. Atkinson. 2007. Interactive learning environments: Contemporary issues and trends. An introduction to the special issue. Educational Psychology Review 19(3): 235-238.

Roble, Dennis B. 2017. Communicating and valuing students' productive struggle and creativity in calculus. Turkish Online Journal of Design Art and Communication 7(2): 255-263.

Rocca, Kelly A. 2010. Student participation in the college classroom: An extended multidisciplinary literature review. Communication Education 59(2): 185-213.

Stigler, James W. and James Hiebert. 2004. Improving mathematics teaching. Educational Leadership 61(5): 12-17.

Thompson, Errol, Andrew Luxton-Reilly, Jacqueline L. Whalley, Minjie Hu and Phil Robbins. 2008. Bloom's taxonomy for CS Assessment. In: Proceedings of the Tenth Conference on 
Australasian Computing Education. Volume 78(January): 155-161. Australian Computer Society, Inc.

Torres, Robert M. and Jamie Cano. 1995. Examining cognition levels of students enrolled in a college of agriculture. Journal of Agricultural Education 36(1): 46-54.

Van Lehn, Kurt, Stephanie Siler, Charles Murray, Takashi Yamauchi and William B. Baggett. 2003. Why do only some events cause learning during human tutoring? Cognition and Instruction 21(3): 209-249.

Warshauer, Hiroko K. 2014. Productive struggle in teaching and learning middle school mathematics. Journal of Mathematics Education 17(4): 3-28.

Warshauer, Hiroko K. 2015a. Strategies to support productive struggle. Mathematics Teaching in the Middle School 20(7): 390-393.

Warshauer, Hiroko K. 2015b. Productive struggle in middle school mathematics classrooms. Journal of Mathematics Teacher Education 18(4): 375-400.

Yin, Robert K. 2017. Case study research and applications: Design and methods. Sage Publications.

Zepke, Nick and Linda Leach. 2010. Improving student engagement: Ten proposals for action. Active Learning in Higher Education 11(3): 167-177.

Zeybek, Zulfiye. 2016. Productive struggle in a geometry class. International Journal of Research in Education and Science 2(2): 396-415. 